\title{
Scientific Publishing with Integrity-The Problems and Its Solutions: Part I
}

\author{
Vinod Krishnan
}

\begin{abstract}
In the modern era where the buzz word is "publish or perish," numerous articles suspicious of misconduct are observed. People often do this out of sheer ignorance of its consequences or to get speedier publication, which lead to both career progression and fame. It is essential that one should be aware of the after-effects of "cut/copy and paste" from another source without giving due credit to the original work, lack of which can lead to serious consequences. This two-part article is intended to make the scientific dental community aware of various forms of misconduct observed as far as scientific publishing is concerned. This also outlines the measures observed so that the amount of plagiarism or misconduct can be minimized or prevented.
\end{abstract}

Keywords: Ethics in publishing, Mosaic plagiarism, Plagiarism, Verbatim plagiarism.

How to cite this article: Krishnan V. Scientific Publishing with Integrity-The Problems and Its Solutions: Part I. Cons Dent Endod J 2016;1(2):25-27.

Source of support: Nil

Conflict of interest: None

\section{INTRODUCTION}

Electronic age has provided us with access to various sources, both useful and harmful, with a click of a mouse. While opening new horizons to the world of information, it has promoted/prompted the novice and senior researchers to adopt various methods to manipulate and fabricate data in scientific publishing. Scientific plagiarism is one of the main problems faced by journal editors and publishers these days, preventing which has become a humongous task. As it is easier to commit these sorts of data manipulation through a simple "cut/copy and paste", one should remember that it is easy to detect with the help of various plagiarism detecting software that are available freely on the Internet. Once detected, the journal editors have the option to retract the manuscript and report the matter to

Professor and Head

Department of Orthodontics, Sri Sankara Dental College Thiruvananthapuram, Kerala, India

Corresponding Author: Vinod Krishnan, Professor and Head Department of Orthodontics, Sri Sankara Dental College Thiruvananthapuram, Kerala, India, e-mail: vikrishnan@yahoo.com the committee on publication ethics (COPE). Committee on publication ethics is the authority that will investigate the case further and, if any fraudulence is observed, to report to the authors' institutional research committee.

\section{WHAT IS PLAGIARISM?}

Plagiarism, the act of fraud, is nothing but stealing one's work and lying about it later. ${ }^{1}$ The word plagiarism has been derived from the Latin word "plagiarius," termed "kidnapper". According to Merriam-Webster Online Dictionary, ${ }^{2}$ plagiarism is defined as "the act of stealing and passing off the ideas or words of other as one's own or to use another's production without crediting the source." This also includes presenting an idea as new or original from a source that already exists. Plagiarism is considered as intellectual theft without any consideration to its intent, quantity, and source from where it is obtained.

\section{WHAT LEADS TO PLAGIARISM?}

Often students and some teachers do it out of sheer ignorance. When one is given an assignment, it is natural resort to Internet search, get some data as well as images and prepare a PowerPoint presentation or make a review article. Doing this act without proper knowledge of copyright issues might lead to legal problems, as violating copyright is considered unlawful. Inadequate knowledge on ethics is considered the main reason behind committing such a crime. ${ }^{3}$ In some instances, people plagiarize because of poor writing skills. In such instances, they use it to create good-quality articles with someone else's words than one's own. With an ambition to catch up with fierce competition in the scientific world, where the key is "publish or perish," one is often tempted to plagiarize. People are often inclined to use this method as it fetches faster publication without much effort. This is often observed in local/state-level journals where chances of detection are slim due to lack of plagiarism checking. Further, even though detected by these journal editors or publishers, the actions taken against the authors are very mild.

\section{WHAT CONSTITUTES PLAGIARISM?}

The simplest form of plagiarism is "verbatim plagiarism," where a word-by-word copy is made from another source

(Source: Reprinted with permission from Scientific Publishing with Integrity Part I, JCAESOK Oct Vol. 2 No. 2) 
without giving proper reference or not putting under quotation marks. ${ }^{4}$ Even if we use our own ideas but has been published previously as part of another article (e.g., copying of material and method section from a previous article), due credit should be given to the original source to respect the copyright statement, which we have signed with the previous publisher. Another similar form of plagiarism is termed "mosaic plagiarism," wherein an article is made from "bits and pieces" obtained from a large number of sources. ${ }^{4}$ In this instance, proper paraphrasing is essential to demarcate the sources clearly and proper citations should be provided to avoid legal actions. Mosaic plagiarisms are common these days and are often the result of poor writing skills and faster generation of articles.

"Inadequate" and "uncited" paraphrasing is also considered as plagiarism in the modern era. You may lift several sentences from one article and put some under quotations and some are claimed as written by yourself. Similary, you might read an article and lift sentences after changing some portions or patch up with some words, without giving proper credit to the original source. The last type of plagiarism is "uncited quotation," where the portion of article lifted from another source is put under quotations but not referenced properly. ${ }^{4}$ In simple terms, one should use their own writing skills to propagate their original ideas and all other methods used or copied from another sources should be given proper credit, so that the other person's effort is also recognized.

\section{SOME CASE EXAMPLES}

A recent report on retraction of a manuscript on "advances in lab-on-chip technology" by Dongqing Li, who holds prestigious Canada research chair at the University of Waterloo, Canada, is a typical example of plagiarism. ${ }^{5}$ $\mathrm{Li}$, along with his student, Yasaman Daghighi, who was nearing her completion of $\mathrm{PhD}$, published a manuscript in "Microfluidics and nanofluidics," which was found to be "unaltered text" from a research report by scientists at Massachusetts Institute of Technology and University of California. They had failed to provide appropriate references to the original sources and the original authors (Bazant and Todd, who published in Journal of Current Opinion in Colloid and Interface Science) stated that "a good chunk of it was a cut and paste job." Li accepted the fact that the article contained plagiarized material and is now facing an investigation by COPE authorities.

Mahesh Visvanathan and Gerald Lushington were directly censored for plagiarism in their three international publications by the US Office of Research Integrity. ${ }^{6}$ The office found out that majority of their research report contained verbatim plagiarism from others' works without proper references. Furthermore, the entire concluding remarks of these articles came from someone else's published work. The authors have faced investigation of this research fraud but could retain their job under agreement that their research will be constantly monitored by the research council of the university. All their publications should now be passed through the monitoring council for the next few years for evaluation for its integrity.

The very famous Dipak Das case from University of Connecticut is another example of data manipulation. ${ }^{7}$ There were 145 plagiarism cases registered against this famous cardiology professor, who was then removed from his position at the university. After plagiarism issue is proved against him, he had faced 11 retractions from the Journal of Cellular and Molecular Biology due suspected "photoshopping" of the images of the benefitting action of reservatrol on cardiac patients and publishing them with proper description of what have been done. Moreover, after finding out this scientific fraud, his grant of almost $\$ 1$ million has been taken back by the federal agency responsible for grant allocation.

Jayant Jagannathan, a neurosurgery resident at University of Virginia, is also facing close monitoring of his works after detecting plagiarism in his published reports. ${ }^{8}$ After finding out that he has plagiarized large amount of text and data from the research reports supported by National Institute of Health, four of his papers were retracted and the fifth paper is planned to be retracted by one major international journal. All his retracted papers were published in major neurosurgery journals, such as Neurosurgery Clinics of North America, Neurosurgical Focus, Neurosurgery, and Biomarkers in Medicine.

Cases have been registered in India as well in a plagiarism row, such as the Gopal Kundu controversy, the Anna University controversy, Prof. Ashok Pandey controversy, and the like. The latest in such came from Prof. CNR Rao, who is the the head of the Scientific Advisory Council to prime minister of India. ${ }^{9}$ Prof. CNR Rao and Prof. Krupanidhi, who were coauthors of the paper by Basant Chithra and Panchakarla titled "Infrared photodetectors based on reduced grapheme oxide and grapheme nanoribbons," stated that the article utilized their name without their knowledge. This brought the matter of "gift authorship" and its relation to plagiarism row to the attention of the scientific community. Majority of the scientific authorities pointed out the serious flaw by the senior authors of the manuscript by not reading it properly before signing the copyright statement. When the discussion heated up, Prof. Rao agreed to withdraw the paper, but the journal refused and agreed to print a correction from the authors that contained an apology. 
Grant Steen, who maintains a blog named "retraction watch,"10 reported that until now 2,047 articles were retracted from biomedical and life science research journals until now. This was based on the research publication that appeared in the Proceedings of National Academy of Sciences (PNAS) recently. The authors further state that "most articles retracted for fraud have originated from the countries with long-standing research traditions (e.g., United States, Germany, and Japan) at the same time duplication and plagiarism arise from countries that lack long-standing research tradition, such as China and India."

\section{PLAGIARISM DETECTION}

Manual detection of plagiarism is very difficult as one has to search through thousands of articles and compare it with the suspected one before finalizing upon the decision. Digital technology has made this effort easy for editors and publishers alike. It is now easy to detect possible plagiarism by simply inserting the suspected sentence, paragraph, or the whole text to the plagiarism detecting program or software. It is at the discretion of the editor or publisher to rate a manuscript as plagiarized as the program will only give a similarity percentage with its database. Up to 20 to $30 \%$ of copying from different sources is considered acceptable by most of the editors, considering the fact that textual overlap often appears while one prepares a manuscript in a particular topic. They often consider the length of the article, the distribution of the textual matter, and the validity of research findings before rating a manuscript as plagiarized. The most common software used by major publishing companies in this regard is iThenticate, which gives a fairly good similarity ratio. There are lot of freeware available, such as "Viper," "Turnitin," "and plagiarism checker" with an agreement that the text used for suspected malpractice will become their property after a certain period of time (depending on the terms of agreement).

\section{PREVENTING PLAGIARISM}

It is the integrity or credibility of a researcher that is reflected in the publications they make. Science has to be considered as divine and its progress can be made when the persons who perform experiments and report it maintain a strict essence of fairness. Salazar ${ }^{11}$ has outlined the various methods through which one can prevent or at least minimize plagiarism as follows:

- Use quotation marks around words taken verbatim from a source

- Change no part of a quotation within the context of a sentence

- Use single quotes for a quotation within a quotation

- Use eclipses (a space and three periods) for a part of quotation omitted
- Use brackets around words

- Limit the use of direct quotes

- Attempt to paraphrase the information, or summarize the information derived from a variety of sources using one's own words.

\section{CONCLUSION}

Plagiarism is venom that is spreading in the publishing world. In an attempt to make faster publicity and acquire fame, young researchers often resort to "cut/ copy and paste." Senior-level researchers, in their urge to scientific progression, often resort to work done by others to write their own manuscripts. Other forms of scientific misconducts, such as data manipulation, authorship conflicts, and redundant/duplicate publications (which are out the scope of this article) do exist among researchers of scientific community. It is the fairness and legitimacy, i.e., expressed through ones' publication and the respect they make out of it. Science has to be dealt with all its true sense if any progress has to be made in one's specialty. It is the responsibility of each one of us to bring in scientific progress through our contribution to our specialty, which is giving us enough to make a good living.

\section{REFERENCES}

1. Website [accessed 2012 Nov 22]. Available from: www. plagiarism.org/assets/downloads/what_is_plagiarism.doc.

2. Website [accessed 2012 Nov 22]. Available from: http:/ / www. merriam-webster.com/dictionary/plagiarize.

3. Website [accessed 2012 Nov 22]. Available from: http:// www.canisius.edu/dotAsset/d075b853-0f52-44dd-a3ad6503ef73fdd0.pdf.

4. Website [accessed 2012 Nov 22]. Available from: http:/ / isites. harvard.edu/icb/icb.do?keyword=k70847\&pageid=icb. page342054.

5. Website [accessed 2012 Nov 22]. Available from: http:// news.nationalpost.com/2012/09/11/university-of-waterlooresearchers-issue-retraction-and-apology-after-using-u-sexperts-text-and-information/.

6. Website [accessed 2012 Nov 22]. Available from: http:/ / www. kansascity.com/2012/01/28/3397752/phony-science-is-agrowing-concern.html.

7. Website [accessed 2012 Nov 22]. Available from: http:/ / www. cbsnews.com/8301-504763_162-57357720-10391704/redwine-researcher-dr-dipak-k-das-published-fake-data-uconn/.

8. Website [accessed 2012 Nov 22]. Available from: http:/ / www. stemcellpioneers.com/showthread.php? $t=5174$.

9. News from The Hindu [accessed 2012 Nov 22]. Available from: http:/ / www.thehindu.com/sci-tech/science/iisc-plagiarismrow-hots-up/article2917125.ece.

10. Website [accessed 2012 Nov 22]. Available from: http:// retractionwatch.wordpress.com/category/grant-steen/.

11. Salazar MK. Using the words and works of others: a commentary. AAOHN J 1993 Jan;41(1):46-49. 